\title{
External Validation of Pretreatment Pathological Tumor Extent in Patients with Neoadjuvant Chemoradiotherapy Plus Surgery for Esophageal Cancer
}

\author{
Sebastian Brinkmann, MD ${ }^{1}$, Bo J. Noordman, MD, PhD ${ }^{2}$, Arnulf H. Hölscher, MD, $\mathbf{P h D}^{1,3}$, \\ Katharina Biermann, $\mathrm{MD}, \mathrm{PhD}^{4}$, David van Klaveren, $\mathrm{PhD}^{5}$, Elfriede Bollschweiler, $\mathrm{MD}, \mathrm{PhD}^{1}$, \\ Katharina Pütz, MD, $\mathrm{PhD}^{6}$, J. Jan B. van Lanschot, $\mathrm{MD}, \mathrm{PhD}^{2}$, and Uta Drebber, MD, $\mathrm{PhD}^{6}$ \\ ${ }^{1}$ Department of General, Visceral and Cancer Surgery, University of Cologne, Cologne, Germany; ${ }^{2}$ Department of \\ Surgery, Erasmus MC - University Medical Centre, Rotterdam, The Netherlands; ${ }^{3}$ Centre for Esophageal and Gastric \\ Surgery, AGAPLESION Markus Krankenhaus, Frankfurt, Germany; ${ }^{4}$ Department of Pathology, Erasmus MC - University \\ Medical Centre, Rotterdam, The Netherlands; ${ }^{5}$ Department of Public Health, Erasmus MC - University Medical Centre, \\ Rotterdam, The Netherlands; ${ }^{6}$ Institute of Pathology, University of Cologne, Cologne, Germany
}

\begin{abstract}
Background. This study was conducted to validate a pretreatment (i.e. prior to neoadjuvant chemoradiotherapy) pathological staging system in the resection specimen after neoadjuvant chemoradiotherapy for esophageal cancer. The study investigated the prognostic value of pretreatment pathological $\mathrm{T}$ and $\mathrm{N}$ categories (prepT and prepN categories) in both an independent and a combined patient cohort.

Methods. Patients with esophageal cancer treated with neoadjuvant chemotherapy and esophagectomy between 2012 and 2015 were included. PrepT and prepN categories were estimated based on the extent of tumor regression and regressional changes of lymph nodes in the resection specimen. The difference in Akaike's information criterion $(\triangle \mathrm{AIC})$ was used to assess prognostic performance. PrepN and ypN categories were combined to determine the effect
\end{abstract}

Sebastian Brinkmann and Bo J. Noordman contributed equally to this work and should be acknowledged with first authorship.

Electronic supplementary material The online version of this article (https://doi.org/10.1245/s10434-019-08024-0) contains supplementary material, which is available to authorized users.

(C) The Author(s) 2019

First Received: 1 March 2019; Published Online: 5 November 2019

B. J. Noordman, MD, PhD

e-mail: b.noordman@erasmusmc.nl of nodal sterilization on prognosis. A multivariable Cox regression model was used to identify combined prepN and ypN categories as independent prognostic factors.

Results. The prognostic strength of the prepT category was better than the $\mathrm{cT}$ and ypT categories ( $\triangle \mathrm{AIC} 7.7 \mathrm{vs}$. 3.0 and 2.9, respectively), and the prognostic strength of the prepN category was better than the $\mathrm{cN}$ category and similar to the ypN category ( $\triangle$ AIC 29.2 vs. -1.0 and 27.9 , respectively). PrepN + patients who became ypN0 had significantly worse survival than prepN0 patients (2-year overall survival $69 \%$ vs. $86 \%$ in 137 patients; $p=0.044$ ). Similar results were found in a combined cohort of 317 patients (2-year overall survival $62 \%$ vs. $85 \% ; p=0.002$ ). Combined prepN/ypN stage was independently associated with overall survival.

Conclusions. These results independently confirm the prognostic value of prepTNM staging. PrepTNM staging is of additional prognostic value to cTNM and ypTNM. PrepN0/ypN0 patients have a better survival than prepN + / ypNO patients.

Potentially curative treatment for esophageal cancer consists of neoadjuvant chemo(radio)therapy followed by surgery. After neoadjuvant therapy, the percentage of residual tumor cells and lymph node regression is of prognostic value. Several studies investigated the impact of tumor regression and classified histopathological response to neoadjuvant therapy and its correlation to prognosis. ${ }^{1-4}$ 
Prior to treatment, clinical staging is known to be relatively unreliable, ${ }^{1,5}$ particularly for the $\mathrm{N}$ category, and an improvement of the pretreatment stage is needed. ${ }^{6}$

Recently, Shapiro et al. ${ }^{7}$ introduced a new staging system based on the pretreatment (i.e. prior to neoadjuvant chemoradiotherapy) pathological tumor extent, which is determined by the extent of regressional changes and the presence of residual tumor cells in the resection specimen. These regressional changes were hypothesized to reflect the pretreatment tumor extent. The authors proved this socalled 'pretreatment pathological $\mathrm{T}$ and $\mathrm{N}$ staging' (prepT and prepN categories) to be estimated reproducibly, with high concordance between three upper gastrointestinal pathologists from different institutes (intraclass correlation coefficient of between 0.7 and 0.9 ). It was demonstrated that the prognostic strength of the prepT category is comparable with the pretreatment clinical $\mathrm{T}$ category (cT category, according to the Union for International Cancer Control [UICC] TNM Cancer Staging, 7th edition ${ }^{7}$ ), while the prognostic strength of the prepN category is even better than the pretreatment clinical $\mathrm{N}$ category ( $\mathrm{cN}$ category), and better predicts overall survival than the post-treatment pathological $\mathrm{N}$ category (ypN category) alone.

The primary aim of the present study was to externally validate the pretreatment pathological staging system of $\mathrm{T}$ and $\mathrm{N}$ stage based on the extent of regressional changes and the presence of residual tumor cells in the resection specimen. In addition, we aimed to study the prognostic value of this new staging system in the post-treatment setting by combining the pretreatment prepN category and the post-treatment $\mathrm{ypN}$ category, to distinguish between patients who were lymph node-negative before neoadjuvant chemoradiotherapy and patients who became lymph node negative thanks to neoadjuvant chemoradiotherapy.

\section{METHODS}

\section{Patient Selection}

Between November 2012 and April 2015, patients treated with curative intent for esophageal or junctional cancer, who underwent neoadjuvant chemoradiotherapy according to the CROSS regimen, and who had an en bloc transthoracic esophagectomy with intrathoracic reconstruction (Ivor-Lewis procedure) at the Department of General, Visceral and Cancer Surgery, University of Cologne (Chairman at that time: Professor Dr. A.H. Hölscher) were included in this study. Patients with nonepithelial tumors and other types of esophageal resection and reconstruction were excluded. According to the recently presented study protocol, ${ }^{1}$ patients who did not receive at least $80 \%$ of the planned dose of neoadjuvant chemoradiotherapy and who received a different neoadjuvant chemoradiotherapy regimen, or patients with an intraoperatively unresectable tumor, were excluded. Patients who had $<80 \%$ of the planned dose of neoadjuvant chemoradiotherapy were also excluded because these patients have limited response due to dose reduction, and not due to tumor biology. However, the group of patients who had $<80 \%$ of neoadjuvant chemoradiotherapy was $<2 \%$ of all patients and therefore likely does not influence the results. Patients did not participate in the CROSS trial. The protocol of the present study was approved by the Ethics Committee of the University Hospital of Cologne (reference number 16-266).

\section{Clinical Staging and Surgery}

Clinical staging consisted of a standardized preoperative work-up, including endoscopy with histological biopsy, endoscopic ultrasonography (EUS), and thoracic and abdominal computed tomography (CT). Clinical $\mathrm{T}$ and $\mathrm{N}$ categories were determined by EUS and CT scanning according to the UICC TNM Cancer Staging, 7th edition. ${ }^{7}$ Patients were classified as $\mathrm{cN}+$ or $\mathrm{cN}-$. For EUS, the criteria for lymph node involvement were a short axis diameter of $\geq 6 \mathrm{~mm}$, a specified hypoechoic pattern or spherical contour and distinct border. On CT, lymph nodes were considered involved if the short axis measurement was $\geq 1 \mathrm{~cm}$, located in the expected distribution, demonstrated altered density or enhancement, and a loss of the fatty hilum could be observed. All patients received neoadjuvant chemoradiotherapy $41.4 \mathrm{~Gy}$ and carboplatin/paclitaxel according to the CROSS regimen. ${ }^{8,9}$ The standard surgical procedure of esophagectomy comprised laparoscopic or open abdominal lymphadenectomy and gastric tube formation, right-sided anterolateral thoracotomy with an en bloc esophageal resection, and two-field lymph node dissection. Reconstruction was performed with a high intrathoracic stapled esophagogastrostomy. The complete surgical approach has been described in detail elsewhere. $^{10,11}$

\section{Post-treatment Pathological Staging}

The resection specimens (primary tumor and all resected lymph nodes) were removed en bloc and analyzed in accordance with a standardized protocol. ${ }^{12}$ Histopathological tumor characteristics were scored using the UICC TNM Cancer Staging, 7th edition. ${ }^{7}$ The adapted Mandard scoring system was used to determine the tumor regression grade (TRG). ${ }^{13}$ 


\section{Pretreatment Pathological Staging}

All resection specimen slides of all patients were examined by two pathologists from the Department of General Pathology and Pathological Anatomy at the University of Cologne. In case of disagreement between the two pathologists, consensus was achieved by consensus discussion. After having proven interobserver agreement of pathological estimations of pretreatment primary tumor extent and lymph node involvement with high reproducibility of prepT and prepN staging in the resection specimen at the Department of Pathology Rotterdam, a meeting of pathologists from both centers was organized to improve validation of the pretreatment pathological staging system. In accordance with Shapiro et al., ${ }^{5}$ the original tumor region, before neoadjuvant chemoradiotherapy, was estimated based on the extent of regressional changes (e.g. fibrosis, mucinous lakes, keratin pearls, and/or foreign body giant cell reactions) and the presence of residual tumor in the resection specimen., 12,14 The 'pretreatment pathological T category' (prepT category), reflecting the estimated original invasion depth of the primary tumor, was based on the extent of regressional changes in the esophageal wall and peri-esophageal stroma. In addition, interpretation of the 'pretreatment pathological N category' (prepN category), reflecting the estimated number of originally involved lymph nodes, was dependent on the presence of regressional changes in lymph nodes. Lymph nodes that showed complete regression (based on pathological examination) without the presence of residual tumor were considered to have been sterilized by neoadjuvant chemoradiotherapy. PrepT and prepN staging were scored using the UICC TNM Cancer Staging, 7th edition. ${ }^{7}$

\section{Data Collection and Follow-Up}

Data were collected from a prospectively maintained database. All patients were regularly evaluated during follow-up, with 3-month intervals within the first year, 6-month intervals within the second year, and an annual aftercare from the third year onwards. Survival was determined by using hospital records. Overall survival was calculated from the day of surgery until the date of death from any cause.

\section{Statistical Analysis}

Data were described using medians and interquartile ranges (IQRs) in the case of continuous variables, or frequencies with percentages in the case of categorical variables.

Prognosis and prognostic strength were based on overall survival data. The difference between Akaike's information criterion of the model and the null model ( $\Delta$ Akaike's information criterion) was calculated to measure the prognostic strength of a model. ${ }^{15} \mathrm{~A}$ higher $\Delta$ Akaike's information criterion value indicates better prognostic ability, adjusted for the statistical complexity of the model fit. It is calculated by the likelihood ratio (LR) Chi square statistic of the corresponding Cox proportional hazards model minus two times the degrees of freedom. PrepN and ypN categories were analyzed as ordinal variables and continuous variables. For models with continuous variables, restricted cubic splines with three knots (corresponding with two degrees of freedom) were used. Kaplan-Meier plots were used to depict survival, and the log-rank test was applied to assess survival differences.

By combining the prepN and $\mathrm{ypN}$ categories, patients were divided into three groups: (1) patients without nodal involvement before and after neoadjuvant chemoradiotherapy (prepNo/ypN0); (2) patients with nodal involvement before neoadjuvant chemoradiotherapy and no detectable lymph node involvement after neoadjuvant chemoradiotherapy (prepN +/ypNo); and (3) patients with nodal involvement before neoadjuvant chemoradiotherapy remaining node-positive even after neoadjuvant chemoradiotherapy (prepN + /ypN + ). To determine the independent association between the combined prepN and ypN categories and overall survival, a multivariable Cox regression model was used. Clinicopathological characteristics, which are known as prognostic factors (i.e. age, sex, histology, TRG, and ypT stage), were included in the multivariable model. All reported $p$ values are two-sided and $p$ values $<0.05$ were considered statistically significant. Statistical analysis was performed using SPSS 21 for Windows (IBM Corporation, Armonk, NY, USA).

\section{RESULTS}

\section{Clinical and Histopathological Characteristics}

Overall, 137 patients were included in this study. Clinicopathological characteristics of patients are displayed in Table 1. Median age at the time of surgery was 62 years; 110 patients were male $(80 \%), 97$ patients had an esophageal or junctional adenocarcinoma (71\%), and 40 patients had an esophageal squamous cell carcinoma (29\%). The majority of patients was clinically staged as cT3 $(90 \%)$ and $\mathrm{cN}+(88 \%)$. In addition, 97 patients were staged prepT3 (71\%) and 82 patients were staged prepN $+(60 \%)$. The median number of resected lymph nodes was 28, with an IQR of 22-35. 
TABLE 1 Clinical and histopathological characteristics of 137 patients with esophageal or junctional cancer treated with neoadjuvant chemoradiotherapy according to the CROSS trial, plus extended surgical resection

\begin{tabular}{|c|c|c|}
\hline & $n$ & $\%^{\mathrm{a}}$ \\
\hline \multicolumn{3}{|l|}{ Age, years } \\
\hline Median (p25-p75) & $62(57-68)$ & \\
\hline \multicolumn{3}{|l|}{ Sex } \\
\hline Female & 27 & 20 \\
\hline Male & 110 & 80 \\
\hline \multicolumn{3}{|l|}{ Tumor type } \\
\hline $\begin{array}{l}\text { Squamous cell } \\
\text { carcinoma }\end{array}$ & 40 & 29 \\
\hline Adenocarcinoma & 97 & 71 \\
\hline \multicolumn{3}{|l|}{ cT category } \\
\hline $\mathrm{cT} 1$ & 2 & 1 \\
\hline $\mathrm{cT} 2$ & 10 & 7 \\
\hline cT3 & 123 & 90 \\
\hline cT4 & 2 & 1 \\
\hline \multicolumn{3}{|l|}{$\mathrm{cN}$ category } \\
\hline $\mathrm{cNO}$ & 17 & 12 \\
\hline cN-positive & 120 & 88 \\
\hline \multicolumn{3}{|l|}{ prepT category } \\
\hline prepT1 & 14 & 10 \\
\hline prepT2 & 26 & 19 \\
\hline prepT3 & 97 & 71 \\
\hline \multicolumn{3}{|l|}{ prepN category } \\
\hline prepN0 & 55 & 40 \\
\hline prepN1 & 34 & 25 \\
\hline prepN2 & 35 & 26 \\
\hline prepN3 & 13 & 9 \\
\hline \multicolumn{3}{|c|}{ Number of nodes resected } \\
\hline Median (p25-p75) & $28(22-35)$ & \\
\hline \multicolumn{3}{|l|}{ ypT category } \\
\hline урт0 & 40 & 29 \\
\hline урT1 & 24 & 18 \\
\hline урТ2 & 22 & 16 \\
\hline урT3 & 51 & 37 \\
\hline \multicolumn{3}{|l|}{ ypN category } \\
\hline ypN0 & 81 & 59 \\
\hline ypN1 & 21 & 15 \\
\hline ypN2 & 27 & 20 \\
\hline ypN3 & 8 & 6 \\
\hline \multicolumn{3}{|c|}{ Tumor regression grade } \\
\hline TRG1 & 40 & 29 \\
\hline TRG2 & 40 & 29 \\
\hline TRG3 & 32 & 23 \\
\hline TRG4 & 24 & 18 \\
\hline TRG5 & & - \\
\hline Missing & 1 & \\
\hline
\end{tabular}

$T R G$ tumor regression grade

${ }^{a}$ Data are expressed as median (interquartile range) or number (\%). Percentages may not add up to 100 because of rounding. The Mandard scoring system was used to determine the $\mathrm{TRG}^{15}$

\section{Comparison of PrepT Category with cT and ypT Categories}

Non-concordant prepT categories (compared with the cT category) were found in 41 of 137 patients (30\%). With regard to the cT category, 37 patients were found to be overstaged. Four patients had a less advanced prepT category compared with the cT category (Table 2a). The prognostic strength of the prep $\mathrm{T}$ category was higher compared with the cT and ypT categories ( $\Delta$ Akaike's information criterion 7.7 vs. 3.0 and 2.9 , respectively) [Table 3]. Overall survival curves according to the cT, prepT, and ypT categories are shown in Fig. 1.

\section{Comparison of PrepN Category with $c N$ and $y p N$ Categories}

Non-concordant prepN categories (compared with the $\mathrm{cN}$ category) were found in 54 of 137 patients (39\%). Overall, 8 patients were clinically staged $\mathrm{cN}$, but showed pathological signs of pretreatment nodal involvement in the resection specimen. In contrast to this, 46 patients were clinically staged $\mathrm{cN}+$, but pathological signs of pretreatment nodal involvement could not be observed (Table $2 b$ ). The prognostic strength of the prepN category was better than the $\mathrm{cN}$ category, and similar to the $\mathrm{ypN}$ category ( $\Delta$ Akaike's information criterion 29.2 vs. -1.0 and 27.9, respectively) [Table 3]. The overall survival curves according to the $\mathrm{cN}$, prepN, and ypN categories are shown in Fig. 2.

\section{Combining PrepN and ypN Categories}

Two-year overall survival in patients without nodal involvement before and after neoadjuvant chemoradiotherapy (group 1) was $86 \%$, compared with $69 \%$ in patients with nodal involvement before neoadjuvant chemoradiotherapy who became node-negative after neoadjuvant chemoradiotherapy (group II) ( $p=0.004)$ [Fig. 3]. Patients who remained node-positive even after neoadjuvant chemoradiotherapy (group III) had the worst survival (2year OS $=44 \%)$ compared with group I $(p<0.001)$. Differences between groups were statistically significant $(p<0.001)$. Patients who had a nodal involvement pretreatment, but became node-negative after neoadjuvant chemoradiotherapy, had a statistically significantly better 2-year overall survival compared with patients who remained node-positive after neoadjuvant chemoradiotherapy $(69 \%$ vs. $44 \% ; p=0.003)$. 
TABLE 2 Comparison of clinical (a) $\mathrm{T}$ and (b) $\mathrm{N}$ categories (cT and $\mathrm{cN}$ categories) with pretreatment pathological $\mathrm{T}$ and $\mathrm{N}$ categories (prep $\mathrm{T}$ and prepN categories) in 137 patients

\begin{tabular}{|c|c|c|c|c|c|c|c|}
\hline & & \multicolumn{5}{|c|}{ PrepT category } & \multirow[t]{2}{*}{ Total } \\
\hline & & 1 & & 2 & & 3 & \\
\hline \multicolumn{8}{|l|}{ (a) } \\
\hline \multirow[t]{4}{*}{ cT category } & 1 & 2 & & 0 & & 0 & 2 \\
\hline & 2 & 3 & & 3 & & 4 & 10 \\
\hline & 3 & 9 & & 23 & & 91 & 123 \\
\hline & 4 & 0 & & 0 & & 2 & 2 \\
\hline \multirow[t]{3}{*}{ Total } & & 14 & & 26 & & 97 & 137 \\
\hline & & \multicolumn{5}{|c|}{ PrepN category } & \multirow[t]{2}{*}{ Total } \\
\hline & & 0 & 1 & & 2 & 3 & \\
\hline \multicolumn{8}{|l|}{ (b) } \\
\hline \multirow[t]{2}{*}{$\mathrm{cN}$ category } & Negative & 9 & 5 & & 3 & 0 & 17 \\
\hline & Positive & 46 & 29 & & 32 & 13 & 120 \\
\hline Total & & 55 & 34 & & 35 & 13 & 137 \\
\hline
\end{tabular}

TABLE 3 Prognostic stratification based on pretreatment clinical $\mathrm{T}$ category, pretreatment pathological $\mathrm{T}$ category, and post-treatment pathological T category, and pretreatment clinical $\mathrm{N}$ category, pre treatment pathological $\mathrm{N}$ category, and post-treatment pathological $\mathrm{N}$ category

\begin{tabular}{|c|c|c|c|c|c|}
\hline & Data type & LR Chi square & $d f$ & $\Delta \mathrm{AIC}^{\mathrm{a}}$ & c-statistic (SE) \\
\hline \multicolumn{6}{|l|}{$\mathrm{T}$ staging } \\
\hline cT category & Ordinal & 7.0 & 2 & 3.0 & $0.55(0.02)$ \\
\hline prepT category & Ordinal & 11.7 & 2 & 7.7 & $0.60(0.03)$ \\
\hline ypT category & Ordinal & 8.9 & 3 & 2.9 & $0.61(0.04)$ \\
\hline \multicolumn{6}{|l|}{$\mathrm{N}$ staging } \\
\hline $\mathrm{cN}$ category & Ordinal & 1.0 & 1 & -1.0 & $0.52(0.02)$ \\
\hline prepN category & Ordinal & 35.2 & 3 & 29.2 & $0.71(0.04)$ \\
\hline ypN category & Ordinal & 33.5 & 3 & 27.5 & $0.69(0.04)$ \\
\hline prepN category & Continuous & 33.9 & 2 & 29.9 & $0.71(0.04)$ \\
\hline ypN category & Continuous & 31.1 & 2 & 27.1 & $0.68(0.04)$ \\
\hline prepN + ypN categories & Continuous & 35.4 & 4 & 27.4 & $0.71(0.04)$ \\
\hline
\end{tabular}

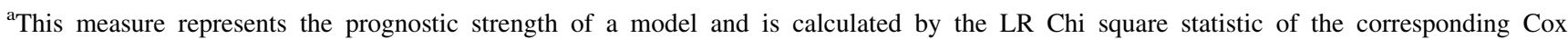
proportional hazards model minus two times the $d f$. A higher $\Delta$ AIC value indicates better prognostic ability, adjusted for the statistical complexity of the model fit $^{17}$

$\triangle A I C$ difference between Akaike information criterion of the model and the null model, LR likelihood ratio, $d f$ degrees of freedom, $c$-statistic concordance statistic, $S E$ standard error

\section{Multivariable Analysis in a Combined Patient Cohort}

Finally, data of all patients from the present study ( $n=137)$, and from the previously reported Rotterdam Study $(n=180),{ }^{7}$ were combined and served as the basis of a multivariable model to prove combined prepN and ypN categories as an independent factor of prognosis. The overall survival curves are shown in Fig. 4. Entering the combined prepN and ypN categories in the multivariable model could identify this additional staging parameter as an independent prognostic factor for overall survival (prepN +/ypN +; hazard ratio [HR] 2.84, 95\% confidence interval [CI] 1.82-4.44; $p<0.01$ ) [Table 4].

Analyses of the prognostic value of overall prepTNM and ypTNM stage grouping showed comparable prognostic strength of prepTNM (classified according to the cTNM classification system) and ypTNM stage grouping ( $\triangle \mathrm{AIC}$ 41.2 and 40.0, respectively; supplemental analyses). 


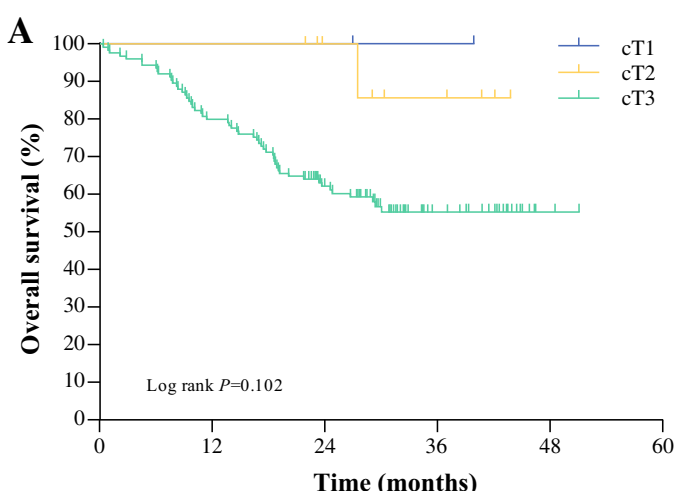

$\begin{array}{lrrrrrr}\text { Numbers at risk } & & & & & \\ \text { cT1 } & 2 & 2 & 2 & 1 & 0 & 0 \\ \text { cT2 } & 10 & 10 & 7 & 4 & 0 & 0 \\ \text { cT3 } & 125 & 100 & 67 & 23 & 2 & 0 \\ \text { Total } & 137 & 112 & 76 & 28 & 2 & 0\end{array}$

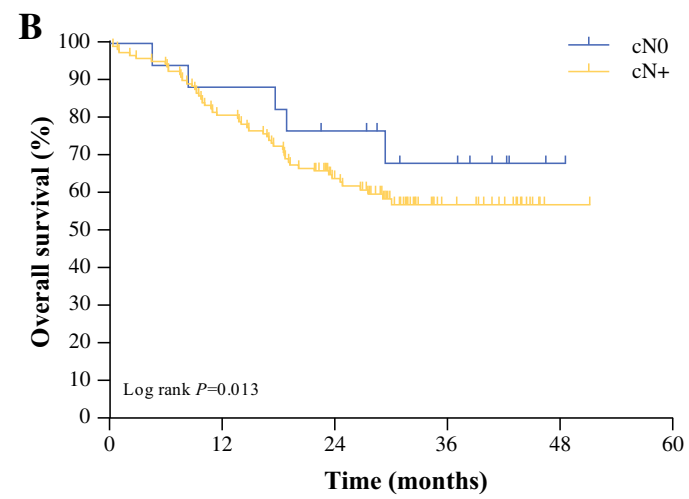

$\begin{array}{lrrrrrr}\text { Numbers at risk } & & & & & \\ \text { prepT1 } & 14 & 14 & 12 & 5 & 0 & 0 \\ \text { prepT2 } & 26 & 25 & 14 & 4 & 0 & 0 \\ \text { prepT3 } & 97 & 73 & 50 & 19 & 2 & 0 \\ \text { Total } & 137 & 112 & 76 & 28 & 2 & 0\end{array}$

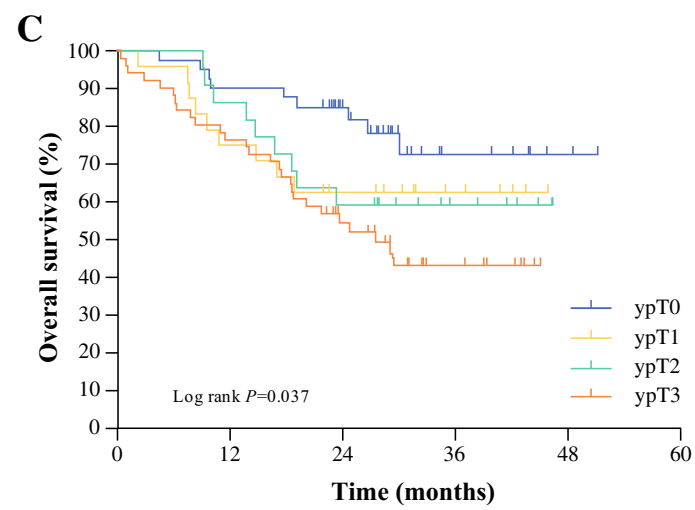

Numbers at risk

$\begin{array}{lrrrrrr}\text { урT0 } & 40 & 36 & 27 & 7 & 2 & 0 \\ \text { урT1 } & 24 & 18 & 13 & 7 & 0 & 0 \\ \text { урT2 } & 22 & 19 & 13 & 6 & 0 & 0 \\ \text { урT3 } & 51 & 39 & 23 & 8 & 0 & 0 \\ \text { Total } & 137 & 112 & 76 & 28 & 2 & 0\end{array}$

4FIG. 1 Overall survival according to a clinical $\mathrm{T}$ category, b pretreatment pathological $\mathrm{T}$ category, and c post-treatment pathological $\mathrm{T}$ category in 137 patients

\section{DISCUSSION}

The present study was conducted to validate the recently presented pretreatment pathological staging system, based on the extent of regressional changes and on the presence of residual tumor cells in the resection specimen. ${ }^{5}$ In an independent cohort of patients treated for esophageal cancer with neoadjuvant chemoradiotherapy followed by surgery at another high-volume center, it was shown that the pathological estimations of the prepT and prepN categories in the resection specimen have a high prognostic power and can therefore be implemented in the pathological assessment.

The present study further aimed to prove the prognostic value of the pretreatment pathological staging system in the post-treatment setting. We confirmed that the prepT and prepN categories have a better prognostic strength than the clinical $\mathrm{T}$ and $\mathrm{N}$ categories. This proves the association of this new staging parameter with postoperative overall survival.

Shapiro et al. found that the prognostic strength of the prepT category is similar to the clinical $\mathrm{T}$ category, but worse compared with the ypT category ( $\triangle$ Akaike's information criterion 1.3 vs. 2.0 and 8.9 , respectively), and the prognostic strength of the prepN category is better than the $\mathrm{cN}$ category, but similar to the ypN category ( $\Delta$ Akaike's information criterion 17.9 vs. 6.2 and 17.2, respectively). In the present study, the prognostic strength of the prepT category was even better than the ypT category. Furthermore, we found the prepN category to have a better prognostic strength than the $\mathrm{cN}$ category.

However, comparing the results of both studies, it has to be mentioned that in the present study, clinical staging of lymph node involvement only differentiated patients in $\mathrm{cN}+$ and cNO. Of 17 clinically node-negative patients, 8 patients $(47 \%)$ showed pathological signs of pretreatment nodal involvement, explaining the low $\Delta$ Akaike's information criterion of the $\mathrm{cN}$ category $(-1.0)$ compared with the prepN and ypN categories. In the study by Shapiro et al., $37 \%$ of patients were clinically staged falsely negative with regard to lymph node involvement. The results of both studies demonstrate the poor N-staging accuracy of CT, EUS, and positron emission tomography (PET)/CT scanning, emphasizing that the clinical estimation of nodal involvement in the preoperative setting is unreliable. This is in line with previous studies reporting similar poor radiological $\mathrm{cN}$ staging accuracy, ${ }^{6,16-18}$ with a sensitivity 
A

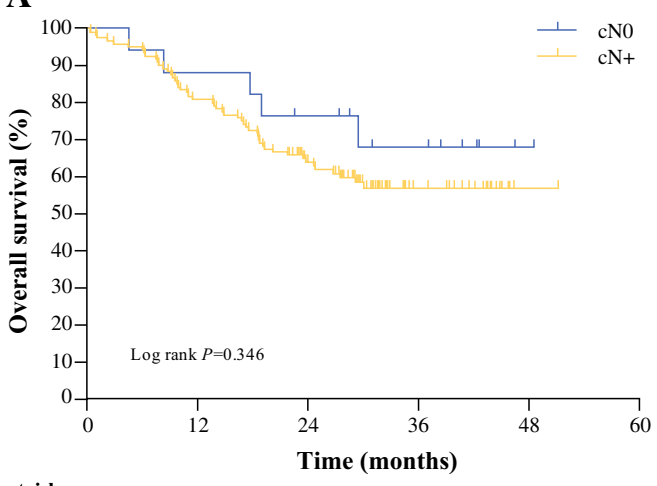

\begin{tabular}{|c|c|c|c|c|c|}
\hline & & & & & \\
\hline Num & & & & & \\
\hline $\mathrm{cN} 0$ & 17 & 15 & 11 & 7 & 1 \\
\hline $\mathrm{cN} 1$ & 120 & 97 & 75 & 21 & 1 \\
\hline Total & 137 & 112 & 76 & 28 & 2 \\
\hline
\end{tabular}

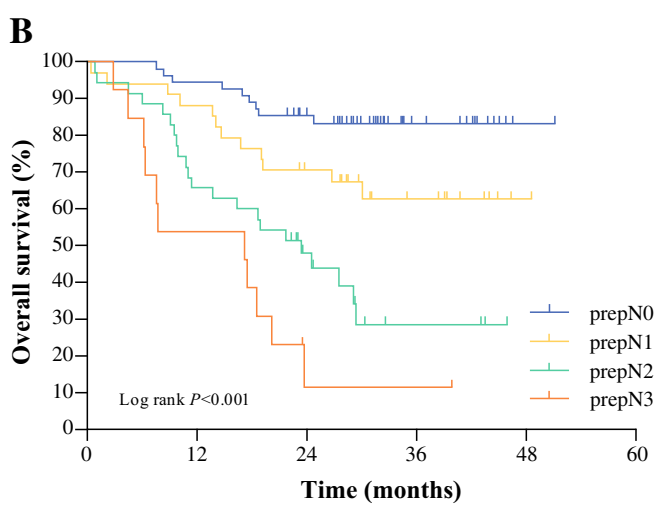

\begin{tabular}{lrrrrrr} 
Numbers at risk & & \multicolumn{5}{l}{ (ime (months) } \\
prepN0 & 55 & 52 & 41 & 14 & 1 & 0 \\
prepN1 & 34 & 30 & 22 & 10 & 1 & 0 \\
prepN2 & 35 & 23 & 12 & 3 & 0 & 0 \\
prepN3 & 13 & 7 & 1 & 0 & 0 & 0 \\
Total & 137 & 112 & 76 & 27 & 2 & 0
\end{tabular}

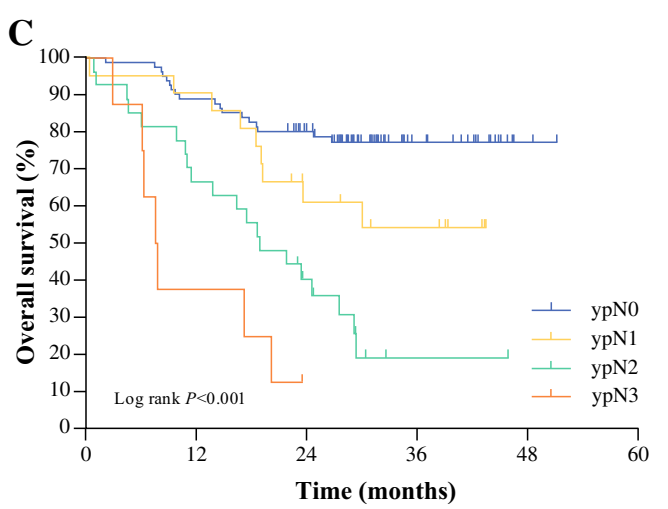

$\begin{array}{lrrrrrr}\text { Numbers at risk } & & & & \\ \text { ypN0 } & 81 & 72 & 56 & 20 & 2 & 0 \\ \text { ypN1 } & 21 & 19 & 11 & 7 & 0 & 0 \\ \text { ypN2 } & 27 & 18 & 9 & 1 & 0 & 0 \\ \text { ypN3 } & 8 & 3 & 0 & 0 & 0 & 0 \\ \text { Total } & 137 & 112 & 76 & 27 & 2 & 0\end{array}$

4FIG. 2 Overall survival according to a pretreatment clinical $\mathrm{N}$ category, b pretreatment pathological $\mathrm{N}$ category, and c posttreatment pathological $\mathrm{N}$ category in 137 patients

and specificity of CT, EUS, and PET/CT of $39.7 \%$ and $77.3 \%, 42.6 \%$ and $75 \%$, and $35.3 \%$ and $90.9 \%$, respectively. ${ }^{17}$

Our study confirms that patients who did not have any pretreatment nodal involvement (prepN0) have a better prognosis than patients who had no residual disease in the resected lymph nodes (ypN0), but who did have pretreatment nodal involvement (prepN +). ${ }^{5}$ This is in contrast with Donohoe et al., ${ }^{3}$ who found that clinically node-positive patients who had complete nodal response had no difference in survival compared with initially clinically node-negative patients. This is probably due to the low accuracy of clinical $\mathrm{N}$ staging. However, in the present study, multivariable analysis proved combined prepN and ypN categories as an independent factor of prognosis. Patients staged prepN + who became ypN0 after neoadjuvant chemoradiotherapy had a significantly worse survival compared with prepN0 patients, with a 2-year overall survival of $62 \%$ vs. $85 \%(p=0.002)$ in the combined group of 317 patients. These findings are in concert with the results of a previously presented study by Nieman et al., ${ }^{19}$ who found a negative prognostic impact of initial nodal involvement even after complete response after neoadjuvant chemoradiotherapy. By staging lymph nodes negative, with no viable cancer cells but the evidence of tumor necrosis in the resection specimen after neoadjuvant chemoradiotherapy, the current TNM staging system is deficient. The previously published data from Shapiro et al., ${ }^{5}$ along with the present results, confirm this thesis as the prognostic value of pretreatment pathological staging of lymph nodes is superior to the conventional post-treatment pathological assessment, and patients staged prepN + have a significant worse survival compared with patients staged prepNO.

The question of clinical relevance of pretreatment pathological staging focuses on the impact of adjuvant therapy in the case of prepN + patients. Recently, Hsu and colleagues studied the benefit of adjuvant treatment in patients with persistent nodal involvement or with an increasing $\mathrm{T}$ category (non-responders) after neoadjuvant chemoradiotherapy, and found an improvement in diseasefree survival in non-responders treated after neoadjuvant chemoradiotherapy, with a significantly reduced rate of systemic recurrence. ${ }^{20}$ For the purpose of sterilizing subclinical lymph node metastases or micrometastases by adjuvant therapy in prepN + patients, but not in prepNO 


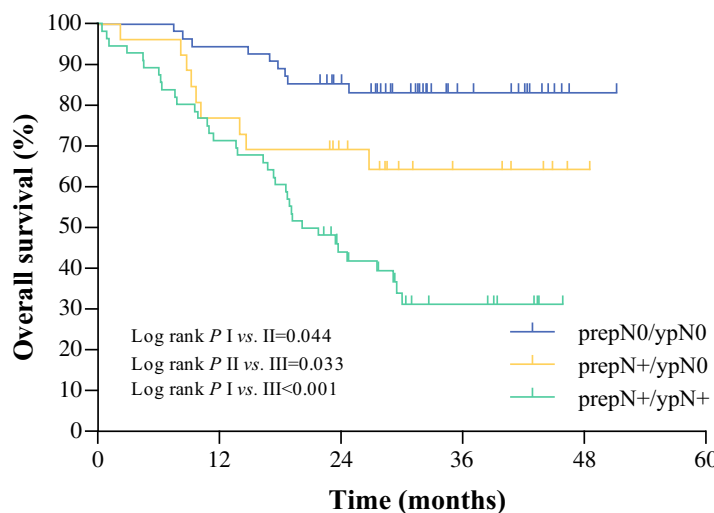

Numbers at risk

$\begin{array}{lrrrrrr}\text { prepN0/ypN0 } & 55 & 52 & 41 & 14 & 1 & 0 \\ \text { prepN+/ypN0 } & 26 & 20 & 15 & 6 & 1 & 0 \\ \text { prepN+/ypN+ } & 56 & 40 & 20 & 8 & 0 & 0 \\ \text { Total } & 137 & 112 & 76 & 27 & 2 & 0\end{array}$

FIG. 3 Overall survival according to the combined scoring of pretreatment pathological $\mathrm{N}$ category and post-treatment pathological $\mathrm{N}$ category in 137 patients. Groups I, II, and III represent prepN0/ypN0, prepN +/ypN0, and prepN +/ypN +, respectively

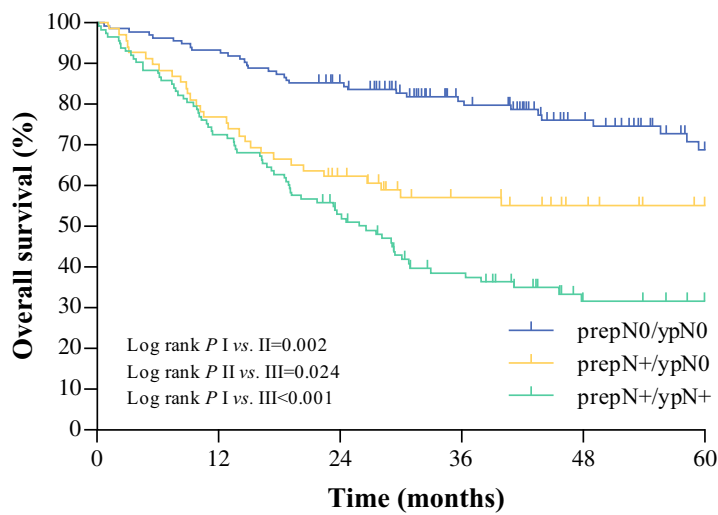

Numbers at risk

$\begin{array}{lrrrrrr}\text { prepN0/ypN0 } & 135 & 126 & 109 & 78 & 52 & 35 \\ \text { prepN+/ypN0 } & 69 & 53 & 40 & 29 & 22 & 17 \\ \text { prepN+/ypN+ } & 113 & 92 & 55 & 34 & 17 & 13 \\ \text { Total } & 317 & 271 & 204 & 141 & 91 & 65\end{array}$

FIG. 4 Overall survival according to the combined scoring of pretreatment pathological $\mathrm{N}$ category and post-treatment pathological $\mathrm{N}$ category in 317 patients from Cologne and Rotterdam. Groups I, II, and III represent prepN0/ypN0, prepN +/ ypN0, and prepN $+/ y p N+$, respectively

patients, this staging system can achieve clinical significance. ${ }^{21}$ Further studies, based on the proposed pretreatment pathological staging, should examine the benefit of adjuvant treatment between different groups of patients according to the prepN categories.
TABLE 4 Multivariable Cox regression analysis of prognostic factors related to survival in 317 patients with esophageal cancer

\begin{tabular}{|c|c|c|c|}
\hline & HR & $95 \% \mathrm{CI}$ & $p$ value \\
\hline Age & 1.03 & $1.01-1.05$ & 0.02 \\
\hline \multicolumn{4}{|l|}{ Sex } \\
\hline Male & 1 (ref) & - & - \\
\hline Female & 0.67 & $0.42-1.05$ & 0.08 \\
\hline \multicolumn{4}{|l|}{ Histology } \\
\hline Squamous cell carcinoma & 1 (ref) & - & - \\
\hline Adenocarcinoma & 0.91 & $0.59-1.41$ & 0.68 \\
\hline \multicolumn{4}{|l|}{ ypT category } \\
\hline урт0 & 1 (ref) & - & - \\
\hline урТ1 & 0.84 (ref) & $0.23-3.01$ & 0.79 \\
\hline урт2 & 0.71 & $0.19-2.65$ & 0.61 \\
\hline урT3/4 & 1.00 & $0.28-3.59$ & 1.00 \\
\hline \multicolumn{4}{|l|}{ Mandard } \\
\hline 1 & 1 (ref) & - & - \\
\hline 2 & 2.08 & $0.58-7.38$ & 0.26 \\
\hline 3 & 2.36 & $0.63-8.88$ & 0.20 \\
\hline 4 & 2.41 & $0.63-9.17$ & 0.20 \\
\hline \multicolumn{4}{|l|}{ Combined prepN and ypN } \\
\hline prepN0/ypN0 & 1 (ref) & - & - \\
\hline prepN +/ypN0 & 2.17 & $1.31-3.58$ & $<\mathbf{0 . 0 1}$ \\
\hline prepN +/ypN+ & 2.84 & $1.82-4.44$ & $<0.01$ \\
\hline
\end{tabular}

Bolded $p$ values are statistically significant (i.e. $p<0.05$ )

Limitations of the present study include the inclusion of patients with both squamous cell carcinomas and adenocarcinomas. These subtypes are biologically different; however, both respond to neoadjuvant chemoradiotherapy and no statistically significant differential effects were found in the CROSS trial. Moreover, there was no interaction with histological subtype $(p$ for interaction $=0.63$ ), suggesting that the effect of the combined prepN and ypN categories is not modified by histology. In the recently introduced 8th edition of the TNM staging system, adenocarcinoma and squamous cell carcinoma are classified differently. Moreover, this revised edition accounts for a new cTNM classification, based on actual clinical stage (rather than re-iterating the pTNM system based on patients who had surgery alone), and a new ypTNM system based on patients receiving neoadjuvant therapy. In the current paper the (obsolete) 7th edition of the TNM staging system was used as this paper is an external validation of a previous study. Therefore, identical methods were applied. ${ }^{5}$ Furthermore, the sample size is relatively limited but was sufficient to validate the initial study and to show that the combined prepN/ypN stage is an independent prognostic factor. 


\section{CONCLUSIONS}

These results independently confirm the previously described prognostic value of the pretreatment pathological staging system. Pretreatment pathological staging is of additional prognostic value to both cTNM and ypTNM and should be considered as a new staging parameter.

FUNDING No sources of funding were used for this research and/ or publication.

DISCLOSURE The authors declare that they have no conflict of interest.

OPEN ACCESS This article is distributed under the terms of the Creative Commons Attribution 4.0 International License (http://crea tivecommons.org/licenses/by/4.0/), which permits unrestricted use, distribution, and reproduction in any medium, provided you give appropriate credit to the original author(s) and the source, provide a link to the Creative Commons license, and indicate if changes were made.

\section{REFERENCES}

1. Holscher AH, Drebber U, Schmidt H, Bollschweiler E. Prognostic classification of histopathologic response to neoadjuvant therapy in esophageal adenocarcinoma. Ann Surg. 2014;260(5):779-84 (discussion 784-5).

2. Schneider PM, Metzger R, Schaefer $\mathrm{H}$ et al. Response evaluation by endoscopy, rebiopsy, and endoscopic ultrasound does not accurately predict histopathologic regression after neoadjuvant chemoradiation for esophageal cancer. Ann Surg. 2008;248(6):902-8.

3. Donohoe CL, O'Farrell NJ, Grant T et al. Classification of pathologic response to neoadjuvant therapy in esophageal and junctional cancer: assessment of existing measures and proposal of a novel 3-point standard. Ann Surg. 2013;258:784-92.

4. Bollschweiler E, Holscher AH, Metzger R et al. Prognostic significance of a new grading system of lymph node morphology after neoadjuvant radiochemotherapy for esophageal cancer. Ann Thorac Surg. 2011;92(6):2020-7.

5. Shapiro J, Biermann K, van Klaveren D et al. Prognostic value of pretreatment pathological tumor extent in patients treated with neoadjuvant chemoradiotherapy plus surgery for esophageal or junctional cancer. Ann Surg. 2017;265(2):356-62.

6. van Vliet EP, Heijenbrok-Kal MH, Hunink MG, Kuipers EJ, Siersema PD. Staging investigations for oesophageal cancer: a meta-analysis. Br J Cancer. 2008;98(3):547-57.

7. Sobin LH, Gospodarowicz MK, Wittekind C, International Union against Cancer, ebrary Inc. TNM classification of malignant tumors. New York: Wiley-Blackwell; 2009. http://site.ebrary.c om/lib/yale/Doc?id=10342913. Accessed 29 Jan 2018.
8. Shapiro J, van Lanschot JJ, Hulshof MC et al. Neoadjuvant chemoradiotherapy plus surgery versus surgery alone for oesophageal or junctional cancer (CROSS): long-term results of a randomised controlled trial. Lancet Oncol. 2015;16(9):1090-8.

9. van Hagen P, Hulshof MC, van Lanschot JJ et al. Preoperative chemoradiotherapy for esophageal or junctional cancer. $N$ Engl $J$ Med. 2012;366(22):2074-84.

10. Holscher AH, Schneider PM, Gutschow C, Schroder W. Laparoscopic ischemic conditioning of the stomach for esophageal replacement. Ann Surg. 2007;245(2):241-6.

11. Schroder W, Holscher AH, Bludau M, Vallbohmer D, Bollschweiler E, Gutschow C. Ivor-Lewis esophagectomy with and without laparoscopic conditioning of the gastric conduit. World $J$ Surg. 2010;34(4):738-43.

12. Schneider PM, Baldus SE, Metzger R et al. Histomorphologic tumor regression and lymph node metastases determine prognosis following neoadjuvant radiochemotherapy for esophageal cancer: implications for response classification. Ann Surg. 2005;242(5):684-92.

13. Mandard AM, Dalibard F, Mandard JC et al. Pathologic assessment of tumor regression after preoperative chemoradiotherapy of esophageal carcinoma. Clinicopathologic correlations. Cancer. 1994;73(11):2680-6.

14. Wheeler JM, Warren BF, Jones AC, Mortensen NJ. Preoperative radiotherapy for rectal cancer: implications for surgeons, pathologists and radiologists. Br J Surg. 1999;86(9):1108-20.

15. Akaike H. A new look at the statistical model identification. IEEE Trans Autom Control. 1974;19:716-23.

16. Monig SP, Schroder W, Baldus SE, Holscher AH. Preoperative lymph-node staging in gastrointestinal cancer-correlation between size and tumor stage. Onkologie. 2002;25(4):342-4.

17. Foley KG, Christian A, Fielding P, Lewis WG, Roberts SA. Accuracy of contemporary oesophageal cancer lymph node staging with radiological-pathological correlation. Clin Radiol. 2017;72(8):693 (e1-e7).

18. van Vliet EP, Eijkemans MJ, Kuipers EJ, Poley JW, Steyerberg EW, Siersema PD. Publication bias does not play a role in the reporting of the results of endoscopic ultrasound staging of upper gastrointestinal cancers. Endoscopy. 2007;39(4):325-32.

19. Nieman DR, Peyre CG, Watson TJ et al. Neoadjuvant treatment response in negative nodes is an important prognosticator after esophagectomy. Ann Thorac Surg. 2015;99(1):277-83.

20. Hsu HY, Chao YK, Hsieh $\mathrm{CH}$ et al. Postoperative adjuvant therapy improves survival in pathologic nonresponders after neoadjuvant chemoradiation for esophageal squamous cell carcinoma: a propensity-matched analysis. Ann Thorac Surg. 2016;102(5):1687-93.

21. Prenzel KL, Holscher AH, Drebber U, Agavonova M, Gutschow CA, Bollschweiler E. Prognostic impact of nodal micrometastasis in early esophageal cancer. Eur J Surg Oncol. 2012;38(4):314-8.

Publisher's Note Springer Nature remains neutral with regard to jurisdictional claims in published maps and institutional affiliations. 